\title{
Holistic Layer of the Enterprise Architecture on the Basis of Process-Driven Organization
}

\author{
Stepan Alexa ${ }^{1 *}$ and Vaclav Repa ${ }^{1}$ \\ ${ }^{1}$ Department of Information Technologies (FIS), University of Economics in Prague \\ W. Churchill Sq. 1938/4, 13067 Prague 3 - Žižkov, Czech Republic \\ stepan.alexa@vse.cz, vaclav.repa@vse.cz
}

\begin{abstract}
Growing complexity of the enterprise ecosystem along with the existence of legacy approaches in the organization can result in a number of challenges when maintaining the solid baseline of its information assets. The digital industry has, over past two decades, passed through rapid evolution triggered both by availability of new technologies, and business as well as operating and funding models. These enablers have direct impact on the way that organizations design and execute their business processes in order to maintain the alignment between their capabilities and targets. This trend implies that enterprises and organizations need to remain flexible by maintaining the alignment of their business and their infrastructure in a dynamically changing and integrated ecosystem. It has been widely recognized that the enterprise architecture as well as the process driven approaches provide tools used by organizations to explain how business, resources and other elements within the organization are related to each other. This article discusses the role, and associated value, that the enterprise architecture and process driven approach have when describing what constitutes the enterprise. At the same time it elaborates on principles and constructs of the model of the holistic layer of the enterprise architecture on the basis of process driven approach. The proposed model aims to combine a unified view on infrastructure and behavior of the enterprise with lean principles in order to identify and focus on key elements of the enterprise.
\end{abstract}

Keywords: Enterprise architecture, process driven organization, business process, WEA (Whole of Enterprise Architecture), service.

\section{Introduction}

An integrated approach, that explains the way the elements making up the enterprise are arranged and orchestrated to achieve business goals, has continuously been a topic for scholars as well as enterprise domain stakeholders. Focus on speed and flexibility in business models and

\footnotetext{
* Corresponding author
}

(C) 2017 Stepan Alexa and Vaclav Repa. This is an open access article licensed under the Creative Commons Attribution License (http://creativecommons.org/licenses/by/4.0).

Reference: S. Alexa and V. Repa, "Holistic Layer of the Enterprise Architecture on the Basis of ProcessDriven Organization," Complex Systems Informatics and Modeling Quarterly, CSIMQ, Issue no. 11, pp. 69-84, 2017. Available: https://doi.org/10.7250/csimq.2017-11.04 
process innovation has resulted in accelerated convergence of the business and information technology domains [1]. The challenge can be observed when orchestrating business processes under the growing complexity of an organization's infrastructure; such as information technology, human and capital resources and so forth [2]. However, from a practical standpoint, the challenge for stakeholders of the organization has seemed to remain the same over past decades. That is to build and maintain a grounded information asset that enables rational decision making about such elements of the enterprise as processes, infrastructure and people; in the context of the organization's goals [3]. Ross, Weill and Robertson define "organizing logic" of the business processes and information technology infrastructure that aims to execute requirements for standardization and integration, based on the operating model used by the organization [4]. In their view the enterprise architecture, in fact, fulfills the role of organizing logic by providing a complete view on systems, resources, business processes and underlying technologies that is aligned with strategic objectives; rather than is just focusing on the organization's current needs. The value of organizing logic, from that perspective, therefore consists in its contribution to achievement of the organization's business goals as concluded also by [5], [6], [7].

This article therefore focuses on understanding the foundation that constitutes the holistic view of the enterprise by combining elements describing its behavior and infrastructure. While a multilayered view of enterprise elements is supposed to be a typical pattern for the enterprise architecture the behavior of the organization is emphasized by the process driven approach. The intersection of those approaches represents the problem statement as depicted on Figure 1. It expresses the fusion of behavioral and infrastructural views on the enterprise and suggests the way it can be used as a cognition tool to further develop the enterprise.

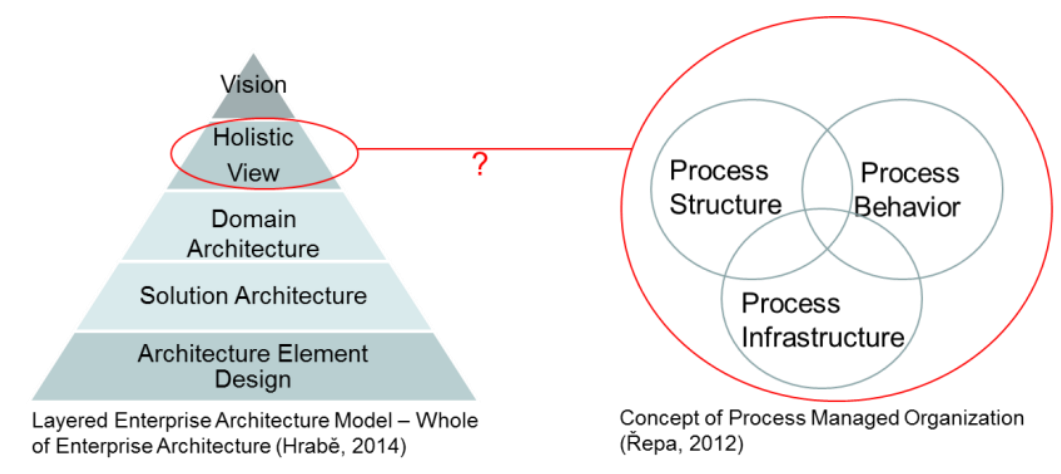

Figure 1. Problem statement

The essence of the problem statement consists in deriving the foundation of how to orchestrate the infrastructure and business processes in the organization towards achieving the business objective by using the right ingredients from both approaches rather than focusing on their pure comparison.

The article is organized as follows. Section 2 is dedicated to literature review while Section 3 provides a grounded baseline for identification of constructs and the principles from both approaches. That is followed by Sections 4 and 5 where the proposed model is initiated and constituted. Section 6 of the article provides the conclusion of the article and outlines further direction of associated research.

\section{Related Work on Holistic Layer of the Enterprise Architecture}

Over decades the Enterprise Architecture has grown into a well-established discipline that aims to provide a complete view of all elements that make up the enterprise. The traditional taxonomic approach represented by Zachman and presented to the public in 1997 approaches enterprise architecture as an abstract concept describing the organization's objects while emphasizing "order and control mechanisms for the development of information systems" [8]. 
Later the enterprise architecture objective was extended towards inclusion of a behavioral dimension in order to describe how companies do their business work [4], [9]. The transition was linked to the challenge of expressing the enterprise elements that constitute the behavioral aspect in the enterprise architecture. Svatos and Repa state that the principle of modeling expresses "the presumption that the objective basis for the implementation of the business system in the organization must be constituted by real facts existing outside of, and independently of, the organization" [10]. Regarding modeling the real world (on the conceptual level), the enterprise architecture as well as the process driven approach recognize two basic dimensions of the real world: structure and behavior. The structural model describes the real world as a system of elements and their mutual relationships while the behavioral (process-oriented) model describes the real world as a system of processes and their substantial relationships. Basic dimensions of the real world are not mutually substitutable but rather complementary: the substance of the real world cannot be expressed via describing behavior just as behavior cannot be expressed via describing structure. However, since both dimensions express the same thing from different points of view, they must be mutually consistent. Similarly, like two basic dimensions, both basic views of the real world are also not mutually substitutable: the system cannot be expressed via describing action details, and detailed time dependencies cannot be expressed via describing the structure of the whole system.

According to Lankorst the Enterprise Architecture is a managerial discipline encompassing both information technology and business with the aim of providing a multi-layered view of the organization through all aspects of its existence [11]. Lankhorst and Osterwalder express the positioning of enterprise architecture within an organization as the way that the enterprise architecture focuses on alignment between the organization's business and information technology; represented by execution of money-making logic and enabling infrastructure [11], [5]. Edhah and Zafar [12] state that the enterprise architecture "translates broader principles, capabilities, and defined business objectives in strategies, into processes that allow the enterprise to realize its objectives".

The information about an organization covering "all objects of an organization without exception" is expressed by a holistic layer of the enterprise architecture [13]. Gala states that the ontological model of an enterprise includes all relevant actualities of an enterprise whilst "ontological model instance represents qualitative and quantitative characteristics of individual enterprise entities" [14]. Model WEA (Whole of Enterprise Architecture) expresses the enterprise architecture layers determined by the level of detail and depth of the enterprise actualities [13]. WEA consists of the following layers:

- Layer 1 - Architectonic vision.

- Layer 2 - Holistic architecture models of the enterprise.

- Layer 3 - Segment and domain architecture models of the enterprise.

- Layer 4 - Domain and project solution architectures.

- Layer 5 - Design and implementation of particular solution elements.

Architectonic vision layer (Layer 1) represents aggregated information that constitutes essential messages of the organization's cognition linked to its future target state. The holistic layer of enterprise architecture (Layer 2) represents the full view of the organization in all aspects of its being. By definition, it needs to reflect both behavioral as well as infrastructural elements of the enterprise. Layer 3 describes the content of enterprise architecture in particular industry domains. Domain and project solution architectures explain elements and their relationships that are linked to concrete programs, projects, or other activities of the enterprise. Layer 5 brings detailed cognition about how to design particular elements of the enterprise architecture such as process, motivator, resource, etc.

Layer 2 explains elements constituting the organization and relations between them at the highest level of abstraction that enables us to describe the full view. The expression of Layer 2 is often referred to as an ontological model of the enterprise and explains how its elements and relations can be depicted at a lower level of abstraction. 
According to Hrabe [13] an organization can be, in that respect viewed as a system (see Figure 2) that:

- Executes the work expressed by service providing architecture in the blue box.

- Needs direction and rules expressed by motivation and control architecture in the orange box.

- Needs resources expressed by assets architecture in the green box.

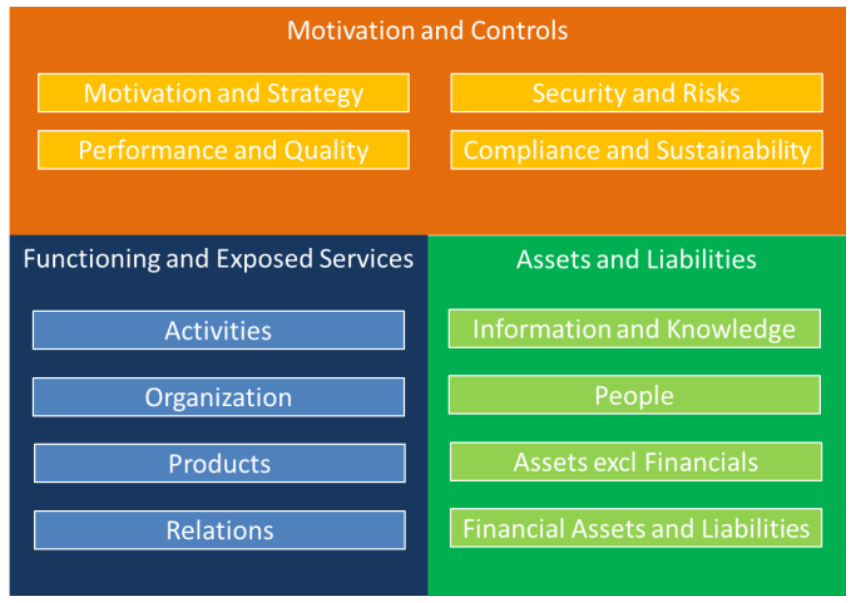

Figure 2. Domain segregation of holistic architecture of an enterprise [13]

The enterprise architecture model presented by Gala defines "people in the enterprise architecture" [15] that includes interested stakeholders and the architectonic team. Hannah and Freeman mention that the stakeholder represents an entity that "can influence achievement of the organization's objectives or one that is influenced by the organization achieving its objectives" [16]. Stakeholders can both receive value from the enterprise and contribute the value to the enterprise. The list of enterprise stakeholders includes shareholders, customers, suppliers, society etc. Typically, the stakeholder acts according to his value measures. Examples of the major value categories for these stakeholders are depicted in following table.

Table 1. Major categories of stakeholder values [17]

\begin{tabular}{|c|c|}
\hline Stakeholder & Value Measures \\
\hline Customer & $\begin{array}{ll}\text { - } & \text { Product/Service Quality } \\
\text { - } & \text { Total Cost of Ownership } \\
\text { - } & \text { Service Access/Acquisition } \\
& \text { Relationship with brand }\end{array}$ \\
\hline Shareholder & $\begin{array}{ll} & \text { Return on Equity } \\
\text { - } & \text { Risk Management } \\
\text { - } & \text { Market Share } \\
\text { - } & \text { Growth Potential }\end{array}$ \\
\hline Employee & $\begin{array}{ll}- & \text { Compensation } \\
\text { - } & \text { Career Management } \\
\text { - } & \text { Work Environment } \\
& \text { Contacts } \\
\end{array}$ \\
\hline Partner & $\begin{array}{ll}\text { - } & \text { Finance } \\
\text { - } & \text { Relationship with Corporation }\end{array}$ \\
\hline Society & $\begin{array}{ll}\text { - } & \text { Finance } \\
\text { - } & \text { Attractiveness of Industry } \\
\text { - } & \text { Corporate Citizenship }\end{array}$ \\
\hline
\end{tabular}

Another building block that constitutes the enterprise architecture is represented by enterprise resource. From the perspective of the business economy theory the enterprise resource can be expressed as a production factor and input to the production process such as human resources, 
financial resources, material, data and others [18]. Based on the International Financial and Reporting Standards (IFRS) representing the financial practice enterprise resources can be classified in the following way [19]:

- Human resources

- Financial resources

- Material resources

- Material

- Infrastructure

- Non-material resources

- Data

- Information

- Know-How

- Technology

- Energy and Utility

- Time

Real enterprise architecture of an organization has a dynamic nature that is determined on the basis of how an organization has been functioning over time. Ross, Weill and Robertson accent process approach in their definition of enterprise architecture as well [4]. According to them, enterprise architecture is an organizing logic of business processes and information technology infrastructure reflecting requirements for integration and standardization based on the operating model of an organization. The same authors add that the operating model expresses the way the enterprise assets are organized in the enterprise. Therefore the enterprise architecture provides a view of business processes, systems, and technologies such that individual activities create capabilities for an organization to align with long term objectives rather than to fulfill immediate goals only.

\section{Process Driven Organization}

The process driven approach was established on the basis of business process engineering and constitutes the theory explaining the business process lifecycle in the enterprise [20], [21], [22]. Business processes are organized and executed to translate targets and strategy into daily routine tasks. As the organizing logic tends to be executed to reflect business objectives, it can be regarded as a major contributor to the overall business strategy [12]. At the high level of abstraction the business architecture defines the value increments achieved through business processes. For instance, during the sales process, value is added by converting an "opportunity" into a "deal" by booking revenue to the organization's account. The business architecture, in fact, describes the way business processes fulfill the business model of the enterprise. Osterwalder [5] sees the business model as the key tool to demonstrate the linkage between business goals, business requirements and the return on investment for key stakeholders. Federal Enterprise Architecture Framework (FEAF) states that its Business Reference Model (BRM) and associated elements "form a key part in delivering expected outcomes and business value to an organization" [23]. According to the Method for Modeling and Analysis of Business Processes [6] the business architecture should conform to business strategy and reflect related challenges.

The first complete explanation of the idea of process management as a style of managing an organization was published in [21]. The major reason for the process-orientation in organization management is the vital need for dynamic organization behavior [20]. That means that any process in the organization should be linked to the customer needs as directly as possible [24]. Hammer emphasizes that the customer need should be represented by a concrete objective linked to a process [25] while Davenport adds that it is desirable to express the objective by using quantitative measures [22]. 
Process arrangement of an organization can be expressed by the structure of the processes „Detailed processes model“ [6] and their mutual process relationships as expressed by „Global processes model" [6]. The way the processes are organized in the enterprise is also influenced by a business model that Osterwalder defines as ,a description of a value a company offers to one or several segments of customers and the architecture of the firm, and its network of partners, for creating, marketing and delivering this value and relationship capital, in order to generate profitable and sustainable revenue streams" [5]. A value the process brings to process consumers is the key factor for the design of the respective process in an organization and it represents a common denominator of different approaches such as Lean Process Framework [26], Value based framework [27], Process based organization [25], [20], [22] - to name a few.

Based on the main idea of process-driven management from [21] the general classification of processes in the organization mainly distinguishes between:

- Key processes, i.e. those processes in the organization which are linked directly to the customer, covering the whole business cycle from expression of the customer need to its satisfaction by the product/service. The rationale of their existence is achievement of the organization's goals.

- Supporting processes, which are linked to the customer indirectly - by means of key processes which they are supporting with particular products/services. Repa mentions that the rationale of their existence is based on the premise that ,these supporting processes provide a service to other processes" in an organization [6].

Key and supporting processes usually coexist in a determined mutual relationship. This is visible from interpretation of Figure 3. It shows that processes may influence each other. The influence can be direct - when processes communicate with each other over a service - or indirect - when processes depend on each other without explicit communication between them. This relation can be set as:

- Structural alignment representing synchronization of a process instance execution with instances of other processes.

- Content-wise alignment representing signalization of data between two processes.

Structural view expresses the relationship between process elements on a basis of object modeling. It determines that there exist mutually related levels of detail that can be used to describe activities of an organization. Some of the authors define the relationship between views of different level of detail as a composition whilst others use hierarchical structure. A basic artifact, in the sense of a process driven approach that provides an interface between the processes, is a service that is an integral part of a global system of processes in the enterprise [28], [20].

Cooperation of processes is a crucial problem in building the global system of processes. Once the basic structure of processes is given, the details of their particular relationships should be analyzed in order to harmonize the cooperation with the internal structure and contents of each process. Structural harmony means the synchronization of the internal process run with the run of individual processes. Content harmony means taking each cooperation point as an act of the communication between both processes. Considering this cooperation point as a service, one can think about both dimensions of the harmony in one: service always means delivering the right product at the right time. Repa [6] emphasizes a value based view of the service that expresses the relevance of the service within the overall ecosystem of the organization and especially in relation to its customers. Key characteristics in that respect are:

- Service subject expressing the purpose of service existence.

- Service consumer who requests the service.

- Service provider who offers the service.

- Service price that combines both objective and subjective perception of the value added. 
The above characteristics need to be formalized in order to set mutually understood expectation about the content that is going to be delivered and associated terms and conditions [29]. Such formalization is provided by the Service Level Agreement (SLA) that expresses the formal contract between service consumer and service provider. Theilmann notes that enterprise service usually consists of one or more subservices composed of activities, functions and infrastructure [30].

Figure 3 shows different problem areas connected with the process based organization. All three viewpoints at Figure 3 together address all substantial parts of the organization's life: content, technology, and people. Each particular point of view is characterized by typical questions which should be answered by the methodology in that field.

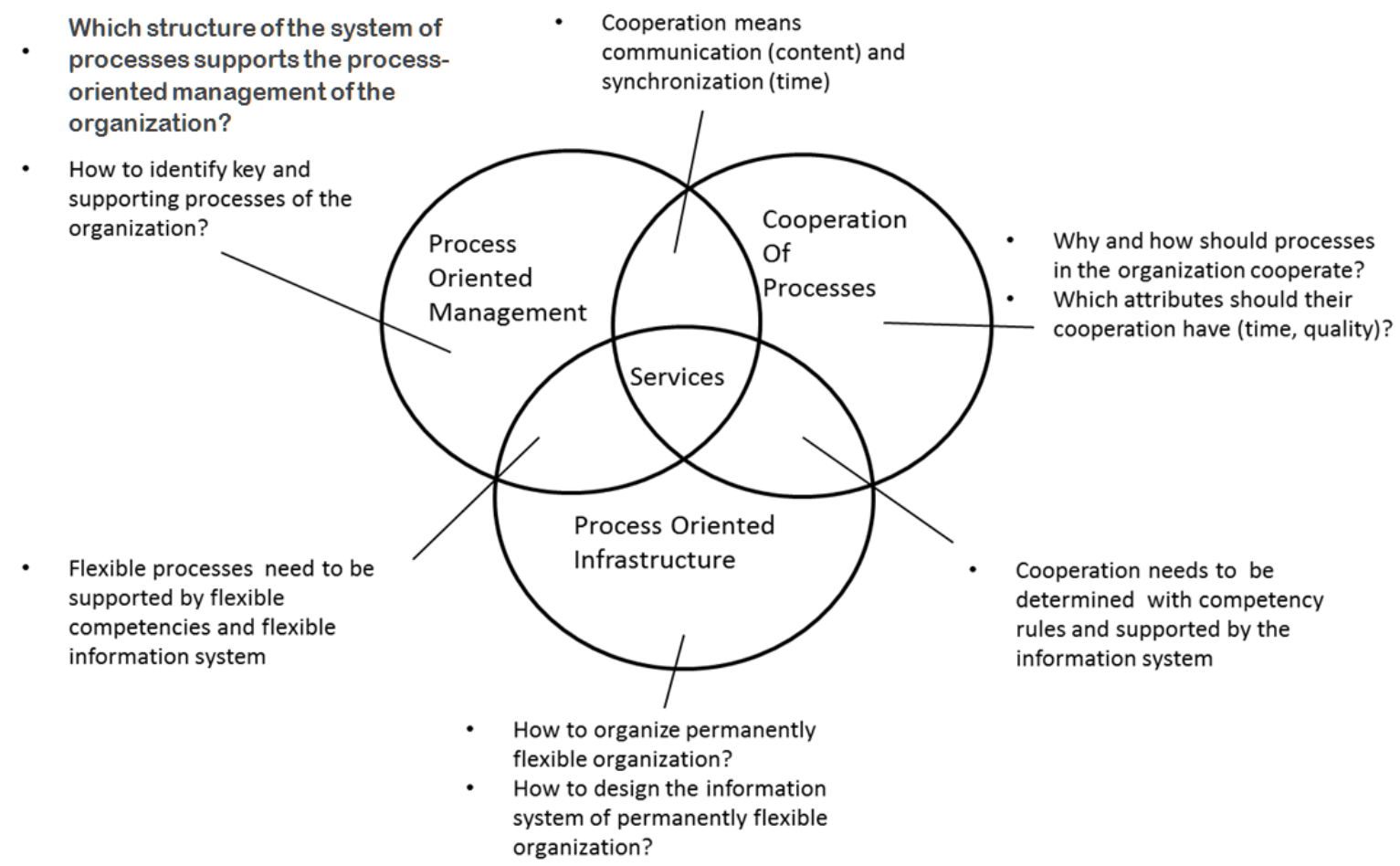

Figure 3. Service as a common denominator of content, technical, and human aspects of the organization management [20]

\section{Initiation of the Proposed Model}

Previous sections of the article were focused on literature review to provide grounded baseline of approaches that analyze behavioral and infrastructural dimensions of the enterprise. As a result of the literature analysis, the authors of this article formulated several principles that influence the constitution of the proposed model. The principles are grouped into two categories. The first set of principles is linked to the enterprise architecture itself and explains its impact on the proposed model and the choice of the elements. The second set of principles is linked to the process driven approach and influences how elements are structured within the proposed model.

In any framework a common denominator of enterprise architecture scope definition can be expressed as the combination of business and infrastructure views. The business view explains how the enterprise operates in order to achieve its business targets while the infrastructure view describes elements that provide all necessary support for business activities. It can be expressed as a principle of completeness.

The enterprise architecture, by definition, exists in every enterprise and it provides transformation of strategic objectives into daily routine activities of the organization. It can be expressed as a principle of expediency. 
The enterprise architecture constitutes the information asset that helps to maintain an adequate level of cognition about the business and infrastructure landscape in daily decision making processes. Gala [14] specifies three dimensions of efficient use of the enterprise architecture as an information asset:

- According to the enterprise lifecycle.

- According to the strategic management phases.

- According to the strategic management roles.

It can be formulated as a principle of efficiency.

As discussed in previous sections, there is a relationship between enterprise architecture and the operating model of an organization. The operating model sets the framework for execution of business for it determines the governance over enterprise assets and key business and supporting processes, as well as roles of key stakeholders [4]. The operating model and the enterprise architecture therefore influence one another and the relationship between the operating model and enterprise architecture has a character of composition. This is supported by the fact that the enterprise architecture includes the enterprise's assets and business processes, as well as stakeholders. It can be expressed as a principle of conformity.

Finally, the enterprise architecture in the organization determines its flexibility in terms of how the changes in arrangement of enterprise elements, and in the structure of individual enterprise elements, support the organization in addressing external and internal influence on the enterprise. It can be expressed as a principle of flexibility. The summary of the first set of principles is shown in Table 2.

Table 2. Principles impacting proposed model

\begin{tabular}{|c|c|}
\hline Name & Expression of purpose \\
\hline Principle of completeness & All elements that make up the enterprise are included \\
\hline Principle of expediency & $\begin{array}{l}\text { Focus of the enterprise architecture is set accordingly with purpose of its } \\
\text { existence }\end{array}$ \\
\hline Principle of efficiency & $\begin{array}{l}\text { The enterprise architecture leads to achievement of the purpose of its } \\
\text { existence }\end{array}$ \\
\hline Principle of conformity & $\begin{array}{l}\text { Business and Operating models are aligned, follow the enterprise's } \\
\text { objectives and make up part of the enterprise architecture }\end{array}$ \\
\hline Principle of flexibility & $\begin{array}{l}\text { The enterprise architecture provides flexible capability enabling the } \\
\text { enterprise to innovate its processes, foresee and mitigate the negative } \\
\text { influence of events coming from the external ecosystem of the enterprise }\end{array}$ \\
\hline
\end{tabular}

The set of principles described below influences the way elements are structured in the proposed model.

The process capability of fulfilling its objective under the influence of external (according to the process) factor changes can be expressed as a principle of sustainability. It combines the assumption that an enterprise as well as a process must have defined objectives that are interlinked with the assumption that it is desirable that the process fulfills its objective in the long term.

The process driven organization keeps its processes lean. Value was introduced as a core concept of the process driven approach supported by a number of other approaches like Value based framework and Lean process framework. Every process, process step, or service needs to generate value that contributes towards achieving the objective; otherwise it represents a candidate for elimination. Therefore authors of this article express it as a Principle of existence of added value to the business process.

It was mentioned, in a number of approaches which were analyzed that the business process represents the way enterprise is functioning internally as well as towards its external ecosystem. The process driven approach defines two basic categories of processes that, together, represent the entire set of activities within the enterprise. Therefore it can be expressed as the Principle of process existence within a process driven organization. 
As was shown in previous sections, processes are linked with one another because the process or activity can hardly exist as standalone. Such a relationship can represent a structural or content-wise alignment between interacting processes. This definition can be set as the Principle of relation existence between processes.

The processes may interact with each other. A service represents an interface between processes in the process driven approach. Therefore interaction of processes should happen over the service in the process driven approach. It can be expressed as the Principle of cooperation between processes.

The summary of the second set of principles is summarized in Table 3.

Table 3. Principles influencing positioning of the behavioral elements in the holistic layer of the enterprise architecture

\begin{tabular}{|l|l|}
\hline \multicolumn{1}{|c|}{ Name } & \multicolumn{1}{c|}{ Expression of purpose } \\
\hline $\begin{array}{l}\text { Principle of existence of relation } \\
\text { between processes }\end{array}$ & Expresses how processes influence one another \\
\hline $\begin{array}{l}\text { Principle of existence of an } \\
\text { individual process value added } \\
\text { within the global system of } \\
\text { processes in the enterprise }\end{array}$ & $\begin{array}{l}\text { Expresses which value brings an individual process for stakeholder or } \\
\text { other process }\end{array}$ \\
\hline $\begin{array}{l}\text { Principle of existence of a process } \\
\text { in process driven organization }\end{array}$ & $\begin{array}{l}\text { Expresses how a process contributes to overall achievement of set } \\
\text { objectives of the enterprise }\end{array}$ \\
\hline $\begin{array}{l}\text { Principle of cooperation between } \\
\text { processes }\end{array}$ & $\begin{array}{l}\text { Expresses content-wise and technical-wise scope of a service as a result } \\
\text { of cooperation between processes }\end{array}$ \\
\hline Principle of process sustainability & Expresses long term capability of the process to fulfill set objective \\
\hline
\end{tabular}

\section{Construction of the Proposed Model}

When comparing resources of cooperation between the processes as depicted at Figure 3 with both structural and content-wise viewpoints, it can be seen that the same principle can be applied to analysis of business processes per se, as well as analysis of relationships between them. This idea is illustrated in Table 4.

Table 4. Structural and content viewpoint expressing unified process view of the organization

\begin{tabular}{|c|l|l|}
\hline & \multicolumn{1}{|c|}{ Business Process } & \multicolumn{1}{c|}{ Cooperation between BP } \\
\hline Structural viewpoint & $\begin{array}{l}\text { Expresses views on business } \\
\text { process on different layers of } \\
\text { abstraction }\end{array}$ & $\begin{array}{l}\text { Expresses synchronization of } \\
\text { process instance execution with } \\
\text { other processes }\end{array}$ \\
\hline Content viewpoint & $\begin{array}{l}\text { Expresses views on the business } \\
\text { process from perspective of its } \\
\text { content and its added value brought } \\
\text { for its consumers }\end{array}$ & $\begin{array}{l}\text { Expresses content alignment by } \\
\text { signalization of data between the } \\
\text { processes }\end{array}$ \\
\hline
\end{tabular}

Since the topic of this article puts together the enterprise architecture and the process approach, then it implies that the constitution of the model itself will be based on both of them. According to the layered model of WEA already described - the proposed model refers to the second layer representing the holistic view of the WEA stack (Figure 1). It therefore reflects the requirement to provide the complete view of the enterprise in order to truly explain elements of the enterprise and the way they are linked and orchestrated. Constructs of the proposed model are expressed in Table 5.

In the introduction section of the article it was said that the article focuses on the holistic view of the enterprise by combining the elements describing behavior and infrastructure dimensions of the enterprise. The behavioral and infrastructural dimensions of the organization were analyzed in sections previous to the two main pillars - enterprise architecture and the process driven 
approach. As a part of model initiation it is therefore necessary to explain the link between derived constructs and both of the above dimensions. Table 6 explains the affinity between the constructs and both dimensions.

Table 5. Constructs of metamodel of the enterprise

\begin{tabular}{|c|c|c|}
\hline Element & Purpose & Source approach \\
\hline Processes & $\begin{array}{l}\text { The enterprise needs to act to achieve } \\
\text { purpose of its existence }\end{array}$ & $\begin{array}{l}\text { Balanced Scorecard, process driven } \\
\text { organization, eTOM, Model WEA, APQC }\end{array}$ \\
\hline Resources & $\begin{array}{l}\text { The enterprise needs resources in order to } \\
\text { be able to act }\end{array}$ & $\begin{array}{l}\text { IFRS, Model WEA, APQC, Theory of } \\
\text { enterprise economy }\end{array}$ \\
\hline Motivators & $\begin{array}{l}\text { Motivators determine the framework } \\
\text { within which the enterprise can act }\end{array}$ & $\begin{array}{l}\text { Balanced Scorecard, Enterprise Governance, } \\
\text { WEA, Value based framework, Maturity } \\
\text { models }\end{array}$ \\
\hline Services & $\begin{array}{l}\text { Interface of cooperating processes or } \\
\text { stakeholders and access enabler to } \\
\text { infrastructure element }\end{array}$ & $\begin{array}{l}\text { Process driven organization, eTOM, Model } \\
\text { WEA }\end{array}$ \\
\hline Stakeholders & $\begin{array}{l}\text { Stakeholders represent entities } \\
\text { influencing how the enterprise acts } \\
\text { towards achieving the objectives that } \\
\text { have been set and the way they are } \\
\text { achieved. }\end{array}$ & $\begin{array}{l}\text { Value based framework, eTOM, enterprise } \\
\text { architecture as a service, process driven } \\
\text { organization }\end{array}$ \\
\hline $\begin{array}{l}\text { Relations } \\
\text { between the } \\
\text { elements }\end{array}$ & $\begin{array}{l}\text { To explain how the enterprise elements } \\
\text { influence each other }\end{array}$ & $\begin{array}{l}\text { Enterprise ontology, Business ontology, } \\
\text { Enterprise architecture as a service, Model } \\
\text { WEA }\end{array}$ \\
\hline
\end{tabular}

Table 6. Affinity of constructs to behavioral and infrastructure dimensions of the enterprise

\begin{tabular}{|c|l|l|}
\hline Element & \multicolumn{1}{|c|}{ Dimension } & \multicolumn{1}{c|}{ Reason } \\
\hline Process & Enterprise's behavior & Process expresses the way the organization operates \\
\hline Resource & Enterprise's infrastructure & $\begin{array}{l}\text { Resource provides an asset that can be drawn by a process } \\
\text { to be able to function }\end{array}$ \\
\hline Service & Enterprise's infrastructure & Motivator sets the grounded baseline for processes to work \\
\hline Stakeholder & Enterprise's infrastructure & $\begin{array}{l}\text { Service expresses the way processes interact with each } \\
\text { other }\end{array}$ \\
\hline $\begin{array}{l}\text { Relation } \\
\text { between } \\
\text { elements }\end{array}$ & $\begin{array}{l}\text { Affineholder itself is an actor with an interest or concern in } \\
\text { the organization. }\end{array}$ \\
\hline
\end{tabular}

The proposed holistic layer of the enterprise architecture essentially conforms with WEA concept whilst proposed contents enhance the layer representing holistic view of the WEA stack. Figure 4 represents the proposed model and expresses the orchestration of constructs and principles depicted in Tables 2 and 3.

In previous sections of this article it was demonstrated that, on the high level of abstraction, in principle, the entire being of the enterprise consists of its motivators, functioning and resources. Later in the article, when the process driven approach was analyzed, it was demonstrated that the functioning of an organization consisted of its processes, services and relations between them; so they represent the same constructs of the proposed model. At the same time the importance of stakeholders, who can act in multiple roles towards the enterprise itself, was mentioned, so the box representing stakeholders was added into the model. Since it was shown in the previous section of the article that the way internal and external stakeholders influence the enterprise is different, this finding was factored into the model as well. Also the enterprise does not function standalone because it needs customers; it probably needs to interact with its suppliers; and also it probably needs to interact with the government and so on. Therefore, as the first thing, the diagram draws the boundary expressing which elements are part of the enterprise and which are 
not. The boundary is shown as a green dashed square. As it was demonstrated earlier, the enterprise architecture of the enterprise is influenced by the external environment so the model also depicts the context of such influence towards the modeled enterprise.

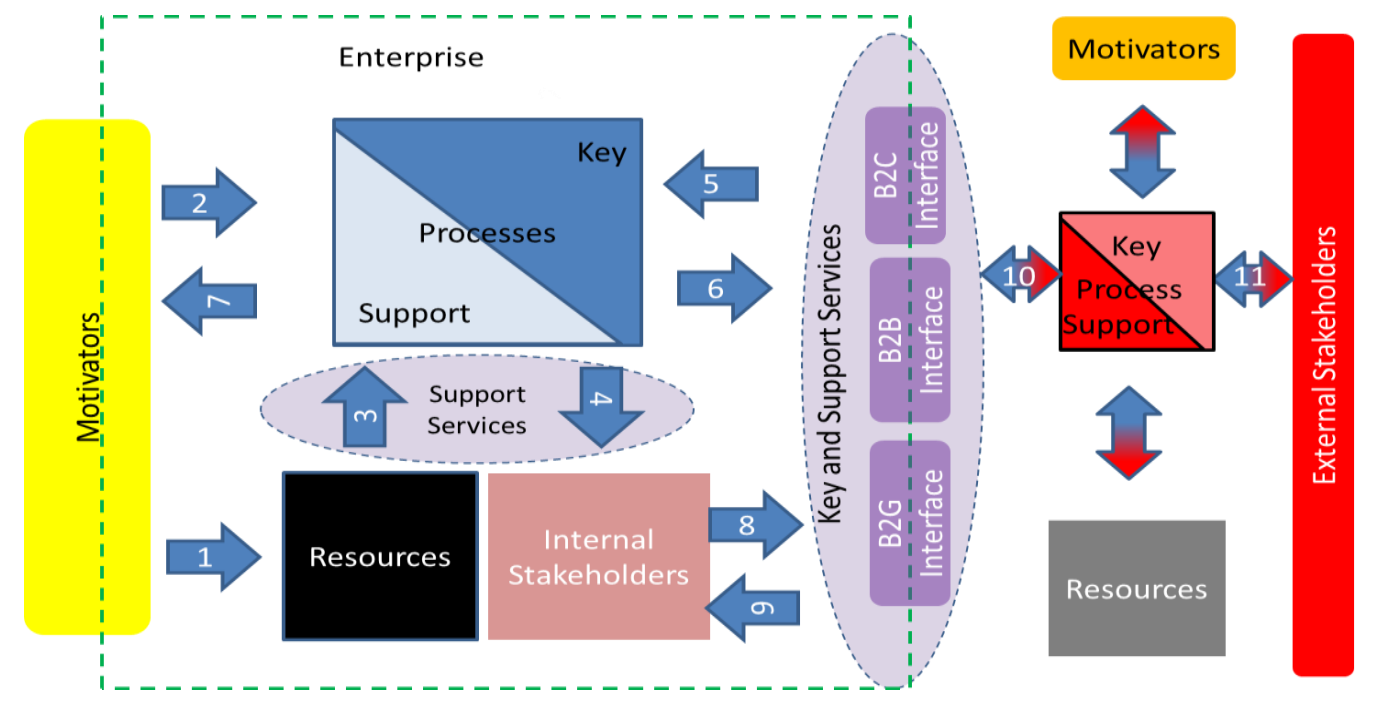

Figure 4. Proposed holistic layer of the enterprise architecture based on process approach

Motivators are shown as a yellow box on the left hand side while part of the box is inside the green square and the rest is outside of it. It reflects the architecture of motivators in a real world scenario. As described earlier, a motivator can be anything that provides incentive, direction, or limits to the enterprise's operations. It can be a strategy, practice, policy, norm, directive, regulation, etc. The motivation can be imposed externally - in case e.g. the regulation is under the ownership of a regulatory entity; or internally - in the case that, the corporate governance is under the ownership of the enterprise as such. Both influence the way the enterprise operates and how its core elements are organized. The arrangement of motivators within the enterprise is represented by the architecture of motivators. The model expresses that the link between the motivator and the resource can be direct. The financial liquidity requirement set by a central bank could be the example of such linkage in the case of a financial institution.

The resources are represented in the model. The arrangement of the enterprise resources demonstrates its static character and resources can be exhaustively classified. However, it seems to be more challenging to express use and lifecycle of these resources in the processes of the enterprise. The proposed model provides a clue for this challenge because it leverages definition of service to facilitate access of a process, or stakeholder, to enterprise resources.

The proposed model supports the view that the functioning of an enterprise can be expressed by a system of its processes and by a system of its services. In compliance with concept of process driven organization all the processes that make up the enterprise can be segregated into key and supporting processes. This is shown as a blue square diagonally divided into a light blue triangle representing the supporting processes and a dark blue one expressing the key processes. Key processes add value for a customer that is monetized by the enterprise and therefore the enterprise can exist only if they are fulfilled. On the contrary, the purpose of supporting processes is to provide a support to other processes. Processes influence one another and this is valid for interaction between processes of the same type and for interaction between processes of different types as well. If we take the general ledger as an example; here is what happens. Events like incoming and outgoing payments are grouped under analytical accounts and then booked to general ledger accounts. Such a function, unless the enterprise does it as a service for its clients, is a supporting process in the area of treasury. Where there is a need for corporate reporting, the treasury department provides a service for the reporting process. In this way the treasury department provides a supporting service to the corporate reporting process which is of a 
supporting type by definition. On the other hand, in a case where the enterprise manages the general ledger for its client, as a service, it is linked to its account receivables process because the enterprise charges a fee to be paid by the client for such a service.

The services in the proposed model are derived from processes by applying the principle of cooperation between processes. They are depicted as violet ellipses in Figure 4 . In the model the service can serve as the interface between processes themselves or also provide access to a resource, stakeholder or motivator as the interface between processes and other enterprise elements. By using this logic, the model expresses that the supporting service enables:

- Access to enterprise resource by a process or stakeholder.

- Access of stakeholder to a process and vice versa.

- Access of stakeholder or process to a motivator.

An example of a supporting service can be provision of enterprise reports within a financial controlling process. Another supporting service can represent access to an IT helpdesk service for other employees of the enterprise within the process of incident management.

In turn, a business service, as per our model, enables bi-directional mediation of value between business process and external (from the viewpoint of the modeled enterprise) stakeholder. The stakeholder can be represented by a physical person, legal entity or business process of external enterprise or organization. A business service thus, e.g. can represent an application function enabling download of a bank statement within the process of customer care. Another business service can be convergent payment enabling a single payment for multiple services of different providers, realized over a uniform payment channel within the process of billing. The arrangement of business and supporting services in the enterprise expresses the service architecture of the enterprise. The services can be provided to internal consumers (process or stakeholder) or to external consumers (process or stakeholder).

When the interaction with the environment, external to the modeled enterprise, is by business processes, the nature and approach of these external interactions is often defined by organizations which are external to the enterprise. The process interactions must then be based on the concept of cooperating processes, which synchronize the internal processes amongst interfacing partners. These processes interact over provided services - a "request" and a "provide" side. Complex interactions of this kind can then be considered to consist of an appropriate set of "request" and "provide" transactions as shown in Figure 5.

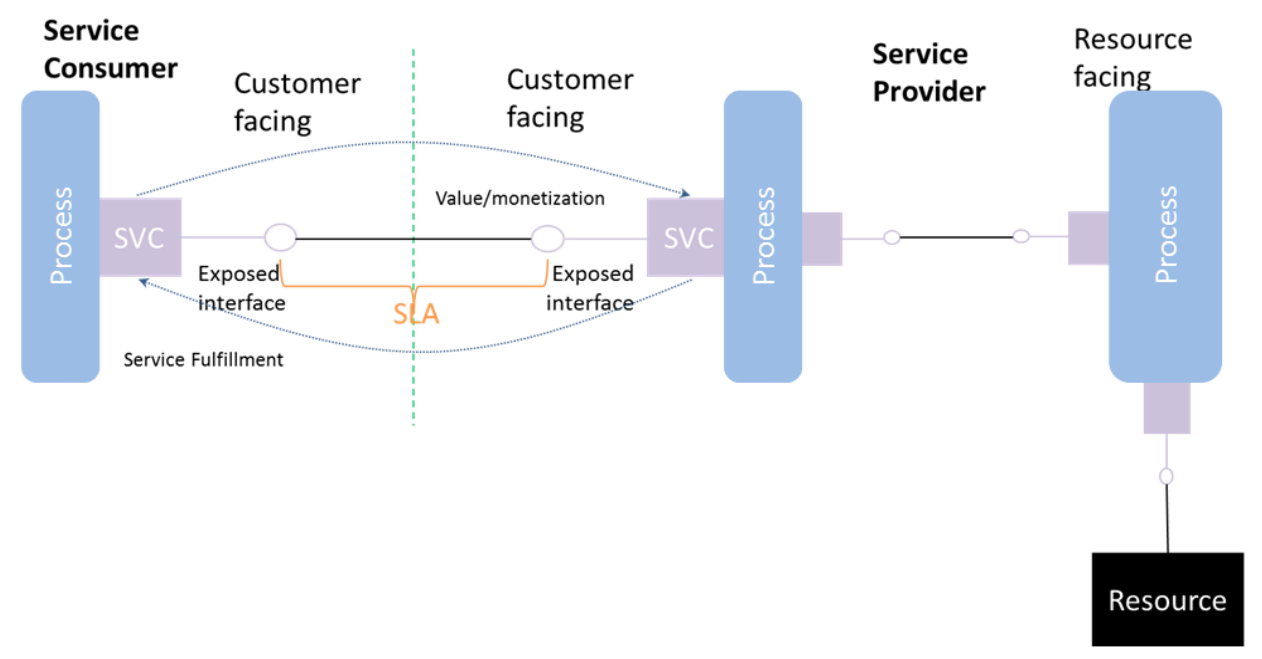

Figure 5. Cooperation between processes over a service

The service consumer expresses the process that has a requirement while the service provider represents the process that provides the service to cover the requirement. The service in conformance with the process driven approach can be either key or supporting. From the perspective of where the service is placed within the interaction chain it can either directly 
communicate with the customer process or it can provide access to the infrastructure. Following such logic the service can be customer facing or resource facing. The service provider fulfills the service for the service consumer and materializes it while the service consumer realizes value from service fulfillment and in turn pays for it. This link is formalized through a contract for customer facing services and was, earlier in the article, defined as SLA, which is also shown in Figure 5.

When the Enterprise is interacting with the external environment, involving the use of Application-to-Application integration on the basis of business processes, these represent the agreement between industry processes to support interaction with customers and partners. Some of these business interactions with external entities may involve third parties such as government, marketplaces, agents, trust providers and similar entities that also form part of this external environment. Such interfaces can be grouped into four essential categories derived from the value framework depicted in Table 1:

- Business-to-Customer (enterprise interacts with the customers - persons).

- Business-to-Business (enterprise interacts with its partners or customers - business entities).

- Business-to-Government (enterprise interacts with entities owned by the government).

- Customer-to-Customer (individuals transacting with one another within the marketplace).

In order to make the description of the model complete, the right hand side of the diagram (Figure 4) has to be explained. In fact this model assumes that the same logic can be used to describe the interfacing organization. There are motivators that set the modus operandi of the organization. Similarly, part are under the governance of the interfacing organization while the rest can be under the governance of the third party entity. Finally, the interfacing organization consists of processes, services as well as resources and stakeholders.

To complete the description, it is also necessary to explain the relationships shown at Figure 4. Table 7 lists these relationships along with their numbers included in Figure 4. Originating element refers to the element in the proposed model that originates the relationship in direction of the arrow. Impacted element refers to the element in the proposed model that is addressed and directly impacted by the relationship.

Table 7. Cooperation between processes over a service

\begin{tabular}{|c|c|c|l|}
\hline ID & $\begin{array}{c}\text { Originating } \\
\text { Element }\end{array}$ & $\begin{array}{c}\text { Impacted } \\
\text { Element }\end{array}$ & \multicolumn{1}{c|}{ Relationship description } \\
\hline $\mathbf{1}$ & Motivator & Resource & $\begin{array}{l}\text { Motivators can influence resources and internal stakeholders } \\
\text { directly. Apart from already mentioned examples the motivators can } \\
\text { also be represented by ethical code, code of business conduct, } \\
\text { incentive scheme and so forth. }\end{array}$ \\
\hline $\mathbf{2}$ & Motivator & Process & $\begin{array}{l}\text { Motivators directly influence processes. The example can be } \\
\text { governance policy that sets the way processes need to be designed } \\
\text { and executed. }\end{array}$ \\
\hline $\mathbf{3}$ & Resource & Process & $\begin{array}{l}\text { Supporting service provide exposure of resources to processes and } \\
\text { stakeholders. The example is IT helpdesk service, service, meeting } \\
\text { booking service and similar. }\end{array}$ \\
\hline $\mathbf{5}$ & Process & Resource & $\begin{array}{l}\text { Condition of resources or stakeholders determines the way processes } \\
\text { and service are designed and executed. New technology can lead to } \\
\text { use of new service or deployment of new process. The example is } \\
\text { deployment of new production line enabling sales on newly acquired } \\
\text { market. }\end{array}$ \\
\hline $\mathbf{6}$ & Process & $\begin{array}{l}\text { External } \\
\text { Process }\end{array}$ & $\begin{array}{l}\text { The enterprise realizes value from external business process through } \\
\text { exposed business service. Such a service can be payment gateway or } \\
\text { order intake }\end{array}$ \\
\hline & Process & $\begin{array}{l}\text { Business process interacts with external business process. Example } \\
\text { can be a service informing customer about availability of goods on } \\
\text { stock or online validation of sold device's ID. }\end{array}$ \\
\hline
\end{tabular}




\begin{tabular}{|c|c|c|l|}
\hline ID & $\begin{array}{c}\text { Originating } \\
\text { Element }\end{array}$ & $\begin{array}{c}\text { Impacted } \\
\text { Element }\end{array}$ & \multicolumn{1}{c|}{ Relationship description } \\
\hline $\mathbf{7}$ & Process & Motivator & $\begin{array}{l}\text { Condition of business process (i.e. fulfillment of set objective) } \\
\text { influences motivators. }\end{array}$ \\
\hline $\mathbf{8}$ & $\begin{array}{c}\text { Internal } \\
\text { Stakeholder }\end{array}$ & $\begin{array}{c}\text { External } \\
\text { Process }\end{array}$ & $\begin{array}{l}\text { Internal stakeholders (i.e. shareholder, employee) are in contact with } \\
\text { partners and customers. This happens as an activity of respective } \\
\text { process. This activity may influence motivators as well as resources } \\
\text { or processes. }\end{array}$ \\
\hline $\mathbf{9}$ & External & $\begin{array}{c}\text { Internal } \\
\text { Stakeholder }\end{array}$ & Same as previous point but reversed \\
\hline $\mathbf{1 0}$ & Process & $\begin{array}{c}\text { External } \\
\text { Process }\end{array}$ & $\begin{array}{l}\text { Reversed view of relation 6 from external organization point of } \\
\text { view. The arrow is bi-directional for sake of model simplicity }\end{array}$ \\
\hline $\mathbf{1 1}$ & External & $\begin{array}{c}\text { External } \\
\text { Stakeholder }\end{array}$ & $\begin{array}{l}\text { External endpoint of the business interaction. External stakeholder } \\
\text { realizes value through his business process interacting with business } \\
\text { process of the other party. }\end{array}$ \\
\hline
\end{tabular}

\section{Conclusion and Further Research}

In this article the authors elaborated on a foundation that can express the holistic layer of enterprise architecture and, at the same time, conforms to the principles of the process driven approach. The first sections of the article were focused on providing a grounded baseline by defining key constructs of the model and constituting the principles derived from the enterprise architecture and process driven approaches. Our research has shown that there are various approaches to express processes within the enterprise architecture and that these show different fit and determination of purpose of the processes in the enterprise's ecosystem.

Availability and capability of new technologies, rapidly evolving business models and dynamically changing enterprise environment are factors that motivate organizations to constantly innovate their business processes while keeping them aligned with their business objectives. Consequently, the enterprise architecture as well as the concept of process driven organization are approaches that are expected by the company executives to provide highly valuable assets and management tools to be used to ensure continuous innovation and to master the content that fits proven practices of the industry and be reflective of its changes.

We realized that the key differentiator that helps to address the abovementioned challenge resides in consistent application of principles of the process driven approach; such as cooperation of processes or focus on contribution to the element's value within the enterprise architecture. The proposed model enables a holistic view of the enterprise itself as well as its interfacing ecosystem. It also explains the orchestration of key elements and the purpose of processes in the organization by determination of key and supporting elements; as well as service fit as the interface and access mediation element.

The other challenge raised in this article required identification and orchestration of elements enabling description of behavior and infrastructure of the enterprise in the proposed model. Coverage of the organization's behavioral dimension was achieved by introducing extended definition of a process and a service on the basis of core concepts of the process driven approach and by positioning of both constructs in the proposed model. Introducing elements such as Internal and External stakeholder and extending the scope of Motivator and Resource in the proposed model helped to explain the purpose and composition of the organization's infrastructural dimension.

It is our conviction that the proposed model helps to bridge the gap between these two approaches because it facilitates the expression of the way organizations are doing their business by preserving the context of the holistic view of the organization. The proposed model addressed, though it did not fully solve, the problem statement mentioned at the beginning of the article. To fully solve the problem an ongoing research should be focused on two areas: first, to derive an ontological model of the enterprise, enabling it to work with the expression of different abstraction levels of the enterprise architecture elements, on the basis of the proposed holistic 
layers, and, second, to propose a method that would provide guidelines for the usage of the proposed model in enterprises by enterprise practitioners.

\section{References}

[1] S.L. Woerner and P. Weill, “Are you the CIO your enterprise needs?” Research Briefing, vol. XVII, no. 1, MIT Center for Information Systems Research, 2017. Available: https://cisr.mit.edu/blog/documents/2017/01/19/2017_0101_cio-time_woernerweill.pdf/

[2] A.J.G. Silvius, "Business and IT alignment in context", dissertation work, University of Utrecht, 2013. Available: https://dspace.library.uu.nl/handle/1874/274784

[3] C. Kluge, A. Dietzch and M. Rosemann, "How to realize corporate value from enterprise architecture", Association for Information Systems: European Conference on Information Systems, 2006. Available: http://aisel.aisnet.org/ecis2006/133/

[4] J.W. Ross, P. Weill and D. Robertson, "Enterprise Architecture as Strategy: Creating a Foundation for Business Execution”, Harvard Business Review Press, ISBN 10: 1591398398, 2006.

[5] A. Osterwalder, "The Business Model Ontology - a proposition in a design science approach", Phd Thesis, $\begin{array}{llll}\text { Universite de } & \text { Lausanne, } & 2004 . & \text { Available: }\end{array}$ http://www.hec.unil.ch/aosterwa/phd/osterwalder_phd_bm_ontology.pdf

[6] V. Repa,: "Information Modelling of Organizations”. Bruckner, Prague, ISBN 978-80-904661-3-5, 2012.

[7] D.J. Nightingale, "Roadmap for Enterprise Transformation", IIE Enterprise Transformation Conference, Atlanta, Georgia, 2012.

[8] J.A. Zachman, "Enterprise architecture: The issue of the century". Database Programming and Design, vol. 10, pp. 44-53, $1997 . \quad$ Available: https://pdfs.semanticscholar.org/f150/1f469e009badc5c9212757cc5a6d24e104c2.pdf

[9] M. Janssen, "Framing Enterprise Architecture: A Meta-Framework for Analyzing Architectural Efforts in Organizations", in: Doucet, G. et al. Coherency Management: Architecting the Enterprise for Alignment, Agility and Assurance. Bloomington: AuthorHouse, pp. 99 - 119, ISBN 978-1-4389-9606-6, 2009.

[10] O. Svatos and V. Repa, "Working with Process Abstraction Levels", in: International Conference on Business Informatics Research. Springer International Publishing, pp. 65-79, 2016. Available: https://doi.org/10.1007/978-3-319-45321-7_5

[11] M. Lankhorst, "Enterprise Architecture at Work, Modelling, Communication and Analysis", Springer-Verlag Berlin Heidelberg, ISBN 978-3-642-01309-6, 2009.

[12] B.S. Edhah and A. Zafar, "Enterprise Architecture: A Tool for IS Strategy Formulation”. continuity, pp. 12, 13, 2016. Available: http://www.mecs-press.org/ijeme/ijeme-v6-n2/IJEME-V6-N2-2.pdf

[13] P. Hrabě, “Koncepce podnikové architektury pro reformu veřejné správy ČR”, disertační práce, VŠE-FIS, Praha, 2014. Availeble: https://theses.cz/id/hz4ki1?lang=en;furl=\%2Fid\%2Fhz4ki1;so=nx

[14] L. Gála, A. Buchalcevová and J. Jandoš, “Enterprise Architecture”, ISBN 978-80-904661-6-6, 2012.

[15] L. Gala, "Enterprise Architecture as a Service", dissertation Thesis, University of Economics in Prague, Praha, 2014.

[16] Michael T. Hannah and John Freeman, "Structural inertia and organizational change", American sociological review, pp. 149-164, 1984. Available: https://doi.org/10.2307/2095567

[17] J. Mize and C. Hallam, "LAI Enterprise Value Stream Mapping and Analysis Working Group: Stakeholder Value Taxonomy", Massachusetts Institute of Technology, Cambridge, 2002.

[18] J.P. Kotter, "Leading Change”, Harvard Business Review Press, Boston, 1996.

[19] Barry J. Epstein and Eva K. Jermakowicz, "Wiley IFRS 2008: Interpretation and Application of International Accounting and Financial Reporting Standards 2008”, John Wiley \& Sons, 2008.

[20] V. Repa, "Role of the Concept of Service in Business Process Management", in: Information Systems Development. New York: Springer, ISBN 978-1-4419-9790-6, pp. 623-634, 2011. Available: https://doi.org/10.1007/978-1-4419-9790-6_50

[21] M. Hammer and J. Champy, "Re-engineering the Corporation: A Manifesto for Business Revolution", Harper Business, New York, NY, 1993. 
[22] T. Davenport, "The Coming Commoditization of Processes", Harward Business School Press, Boston, 2005. Available: https://hbr.org/2005/06/the-coming-commoditization-of-processes

[23] U.S. Federal CIO Council, Federal Enterprise Architecture Framework, 2013. Available: https://www.whitehouse.gov/omb/e-gov/fea

[24] OpenSoul Project, 2000 - 2016. Available: http://opensoul.panrepa.org

[25] M. Hammer, “The Process Audit”, Harvard Business Review, 2007.

[26] D.J. Nightingale, "Principles of Enterprise Systems", MIT Lean Advancement Initiative, Second International Engineering Systems Symposium, 2009. Available: https://dspace.mit.edu/handle/1721.1/84550

[27] E. Murman, T. Allen, K. Bozdogan, J. Cutcher-Gershenfeld, H. McManus, D. Nightingale and J. Warmkessel, "Lean enterprise value. Insights From Mit's Lean", 2002. Available: https://doi.org/10.1057/9781403907509

[28] M. Zimmermannová and V. Repa, "Vztah procesního řízení a Enterprise Architecture”, Systémová integrace, vol. 18, no. 4, pp. 7 - 21, 2011. Available: http://www.cssi.cz/cssi/vztah-procesniho-rizeni-enterprisearchitectur

[29] N.R. Jennings, “Autonomous agents for business process management”, Applied Artificial Intelligence, vol. 14, no. 2, pp. 145-189, 2000. Available: https://doi.org/10.1080/088395100117106

[30] W. Theilmann, “A Reference Architecture for Multi-Level SLA Management”, Journal of internet engineering, vol. 4, no. 1, December 2010.

Additional information about the article:

\begin{tabular}{|l|l|}
\hline \multirow{2}{*}{ Author ORCID iD } & $\begin{array}{l}\text { Stepan Alexa }- \text { n/a on 26 July 2017 } \\
\text { Vaclav Repa }- \text { www.orcid.org/0000-0001-9113-3447 }\end{array}$ \\
\hline & Received 22 April 2017 \\
Article history & Revised 13 July 2017 \\
& Accepted 16 July 2017 \\
& Available online 31 July 2017 \\
\hline Article PII & S225599221700065X \\
\hline
\end{tabular}

